\title{
SOLUBILITY OF CALCIUM SILICATE BASED CEMENTS - A COMPARATIVE STUDY
}

\author{
Y. Kouzmanova, I. Dimitrova \\ Department of conservative dentistry, Faculty of Dental Medicine, Medical University - Sofia, Bulgaria
}

\begin{abstract}
Calcium silicate based cement is a group of biomaterials, based on Portland cement. Its physicochemical properties such as solubility are of the utmost importance. It should have low solubility in tissue fluid since the dissolution of materials may lead to treatment failure. The aim of this study is to evaluate the solubility of five calcium silicate cements after being placed in distilled water for a period of 28 days. Material and methods: The purpose of this study was to compare solubility of a four new calcium silicate-based cements, such as: gray MTA Angelus; white MTA Angelus; BioAggregate and Biodentine with conventional mineral trioxide aggregate White ProRoot. Solubility is evaluated using standardized samples of materials, which are weighed before and after 28-day immersion in distilled water. Results: The lowest solubility is found at White ProRoot and the significantly highest solubility - at Biodentine.
\end{abstract}

Key words: new calcium silicate based cements, solubility, conventional mineral trioxide aggregate.

Correspondence address: Y. Kouzmanova, Faculty of Dental Medicine, Department of Conservative Dentistry, 1 Georgi Sofiyski Street, 1431 Sofia, Bulgaria, e-mail: vanja_ves@abv.bg

\section{INTRODUCTION}

Calcium silicate based cements are a group of biomaterials, based on Portland cement. Mineral Trioxide Aggregate (MTA), such as ProRoot MTA (Dentsply Tulsa Dental Specialties, Tulsa, OK, USA) was introduced in the 1990s [1] followed later by MTA Angelus (Angelus, Londrina, Brazil). The new materials have been claimed to have all the advantages of conventional MTA without any of its drawbacks. More recently materials based on calcium silicate cement have been introduced in dentistry. Biodentine (Septodont Ltd., Saint Maur des Fausse's, France) is a new tricalcium silicate based inorganic commercial cemen t[2, 3]. Bioaggregate (Innovative BioCeramic, Vancouver, Canada) is a relatively new product containing calcium silicate hydrate, calcium hydroxide [4]. These products are used for repair of iatrogenic root perforations occuring during clinical root canal procedures [5]. Hermetic sealing ability is a basic requirement for this group of materials. It is a complex result of several factors - marginal adaptation, adhesion, solubility and dimensional changes[6]. Its physicochemical properties such as solubility are of the utmost importance. It should have low solubility in tissue fluid since the dissolution of materials may lead to treatment failure [5]. Slightly contradictory is the available information in the literature on the solubility of calcium silicate based cements [9, 10, 13].

The aim of this study is to evaluate the solubility of five calcium silicate cements after immersion in distilled water for a period of 28 days.

\section{MATERIAL AND METHODS}

This study was performed using five calcium-silicate cements: group 1 - white ProRoot MTA (Dentsply, Maille- 
fer, Swisse); group 2 - gray MTA-Angelus (Angelus, Londrina, Brazil); group 3 - white MTA-Angelus (Angelus, Londrina, Brazil); group 4 - BioAggregate (IBC, Canada); group 5 - biodentine (Septodont, France).

All calcium silicate cements were mixed according to the manufacturer's instructions in ratio 3:1 powder-toliquid on a glass slab with cement spatula to produce homogeneous paste and inserted into cylindrical molds in internal diameter $15 \mathrm{~mm}$ and height $4 \mathrm{~mm}$. The surface of the samples was smoothed with Mylar strip. On this surface a wet cotton pellet was placed in contact with cement for 4 hours to provide the necessary additional humidity for the normal course of the hydration and setting process.

Biodentine is prepared by adding the liquid to the powder present in the capsule. These components are then triturated with an amalgamator for $30 \mathrm{~s}$ at $4000 \mathrm{rpm}$ leading to the formation of a paste of creamy consistency.

The speciments were placed then in a vacuum dessicator for 3 days to evaporate excess moisture. The samples were weighed in an analytical balance Sartorius with accuracy of $\pm 0,0001 \mathrm{~g}$. Then they were placed in $20 \mathrm{ml}$ distilled water for 28 day.

After this period the test samples were removed from the distilled water and evaporated in a furnace at a temperature below the boiling point. The weight of the crucible with the residual dry matter was measured with the balance. It takes away the weight of the empty crucible. The solubility was calculated as a percentage by weight of the dry matter divided by the initial weight of the samples and multiplied by 100 .

The solubility of each tester was determined by the following formula

Solubility $\%=\frac{\text { weight of the dry matter }}{\text { the initial weight of the samples }} \times 100$

\section{Statistical analysis}

All data was processed with a IBM SPSS Statistics 19.0. For a significance level in which the zero hypothesis was rejected, $p<0.05$ was selected. The following methods have been applied: 1) descriptive analysis - when tabulated the frequency distribution of the studied groups, rare anatomical variations; 2) alternative analysis - for comparing relative shares.

\section{RESULTS}

The results are presented in Table 1.

The different digits are a sign of a statistically significant difference

The lowest solubility was recorded in ProRoot $2.90 \%$ and the highest in Biodentine $-18.72 \%$. A statistically significant difference was seen with ProRoot and gray Angelus, on the one hand, and white Angelus and Bioaggregate, on the other. There is also a statistically significant difference between Biodentine and all other cements.

\section{DISCUSSION}

The solubility of calcium silicate materials is of particular importance because they are expected to provide hermetic sealing ability in contact with blood and tissue fluids [7]. According to ANSI/ADA (American National Standards Institute/American Dental Association) specification 57, the requirements for the solubility of the root-filling agents are not to exceed $3 \%$ [ANSI/ADA]. The ISO 6876 standard is also 3\% [8].

The results found by us show only such solubility in ProRoot $-2.90 \%$ and in all other materials the solubility is increased. The highest solubility in Biodentine is $18.72 \%$. There is a statistically significant difference between different materials.

Unlike us according to Grech and et al [9] Bidentine and Bioaggregate have very low solubility, with no

Table 1

\begin{tabular}{|c|c|c|c|}
\hline $\begin{array}{l}\text { Materials } \\
\text { Solubility }\end{array}$ & The initial weight of the samples & $\begin{array}{l}\text { The weight of dissolved } \\
\text { material }\end{array}$ & $\begin{array}{c}\% \text { dissolved } \\
\text { material }\end{array}$ \\
\hline ProRoot MTA & 1,0360 & 0,0301 & $2,90 a$ \\
\hline W MTAAngelus & 1,0400 & 0,0562 & $5,40 \mathrm{~b}$ \\
\hline G MTA Angelus & 1,0037 & 0,0394 & $3,92 a$ \\
\hline Bioaggregate & 0,8126 & 0,0471 & $5,82 b$ \\
\hline Biodentine & 1,1119 & 0,2082 & $18,72 \mathrm{c}$ \\
\hline
\end{tabular}


statistically significant difference between them. A Saghiri et al. reported that the solubility of Bioaggregate is $2.15 \%$ and white ProRoot MTA is $0.87 \%$ [10].

The literature reports that ProRoot has low or no solubility [11]. However, it has been observed in some studies that the solubility increases with time [12].

Similar to our results, Singh et al [13] reported that Biodentine have significantly higher solubility than ProRoot for 30- and 60-day immersion periods. Likewise, similar data reported Kumari, et al [14].

Roberti Garcia et al [15] found that white MTA-Angelus $(6.65 \%)$ had a higher solubility than the gray formulation. Similar data is reported from Borges [16]. Moreover, Borges also noted that the white ProRoot MTA was also more soluble than the gray one. Comparing white and gray MTAs, the white version of the cement exhibited greater solubility [17]. Although bismuth oxide is an insoluble substance, the presence of this substance in the composition of MTA may be responsible for the solubility of the cement due to the fact that bismuth oxide causes a deterioration of the mechanical strength and it increases the relative porosity of the material [1].

Water absorption studies of materials are related to their solubility. According to Bortoluzzi et al [19] one of the disadvantages of MTA is its tendency to wash off or disintegrate in early contact with blood and other tissue fluids.

\section{CONCLUSION}

The solubility of five calcium-silicate cements in distilled water for a period of one month is compared. After analysis of our solubility results we can make the following conclusions: 1. ProRoot has the lowest solubility at the end of the first month $-2.90 \%$. 2. Biodentine has shown the highest solubility $-18.72 \%$.

\section{REFERENCES}

1. Torabinejad M, Hong CU, McDonald F et al. Physical and chemical properties of a new root-end filling material. J. Endod. 1995, 21(7), 349-353.

2. Camilleri J. Investigation of Biodentine as dentine replacement material. J. Dent. 2013, 41(7), 600-610.
3. Asgary S, Shahabi S, Jafarzadeh $\mathrm{T}$ et al. The properties of a new endodontic material. J. Endod. 2008, 34(8), 990-993.

4. Camilleri J. In: Mineral Trioxide Aggregate in dentistry from preparation to applications, 2014, Springer Heidelberg New York Dordrecht London

5. Primus MC, James L, Gutmann RYet al. Physical Properties of New Generation Tricalcium Silicate Dental Materials. Bioceram Dev Appl 2014, 4, (1), 2-9.

6. Torabinejad M, Chivian N. Clinical application of mineral trioxide aggregate. J. Endod. 1999, 25(3), 197-205.

7. Poggio C, Lombardini M, Alessandro $\mathrm{C}$ et al. Solubility of rootend-filling materials: A comparative study. J. Endod., 2007, 33(9), 1094-1097.

8. ANSI/ADA. Specification no. 57: endodontic sealing materials. Chikago, IL: ANSI/ADA; 2000

9. Grech L, Mallia B, Camilleri J. Investigation of the physical properties of the calcium silicate cement-based root-end filling materials. Dent. Mater., 2013, 29, e20-28.

10. Saghiri MA, Godoy FG, Gutmann JL et al. The effect of solubility of nano-modified endodontic cements. J. Conserv. Dent., 2014, 17(1), 13-17.

11. Danesh G, Dammaschke T, Gerth HU et al. A comparative study of selected properties of ProRoot mineral trioxide aggregate and two Portland cements. Int Endod J. 2006,39, 213-219.

12. Fridland M, R. Rosado. MTA solubility: a long term study. J Endod. 2005, 31, 376-379.

13. Singh S, Podar R, Dadu S et al. Solubility of a new calcium silicate-based root-end filling material. J. Pakistan Dent. Ass. 2015, 18,(2), 149-153.

14. Kumari S, Mittal A, Dadu S et al. Comparative Evaluation of Physical and Chemical Properties of Calcium Silicate Based Root End Filling Materials (Mineral Trioxide Aggregate and Biodentine): An in vitro Study. Indian Journal of Dental Sciences, 2018, 10, (4), 197-202.

15. Roberti Garcia, Lda F, Chinelatti MA, Rossetto HL et al. Solubility and desintegration of new calcium aluminate cement (EndoBinder) containing different radiopacifying agents. J. Endod. 2014, 40(2), 261-265.

16. Borges $\mathrm{AH}$, Pedro FL, Miranda CE et al. Comparative study of physico-chemical properties of MTA-based and Portland cements. Acta Odontol. Latinoam., 2010, 23(3), 175-181.

17. Chang SW, Baek SH, Yang HC et al. Heavy metal analysis of ortho MTA and ProRoot MTA. J Endod. 2011, 37, (12), 1673-1676.

18. Islam I, Chng HK, Yap AU. Comparison of the physical and mechanical properties of MTA and Portland cement. J Endod. 2006, 32, 193-197.

19. Bortoluzzi EA, Broon NJ, Bramante CM et al. Sealing ability of MTA and radiopaque Portland cement with or without calcium chloride for root-end filling. J. Endod. 2006, 32(9), 897-900.

Received April, 2019 - Revised May, 2019 Accepted June, 2019 